\title{
Mutations in transglutaminase 1 gene in autosomal recessive congenital ichthyosis in Egyptian families
}

\author{
R.M. Shawky ${ }^{\mathrm{a}}$, N.S. Sayed ${ }^{\mathrm{b}}$ and N.A. Elhawary ${ }^{\mathrm{b}}$ \\ ${ }^{a}$ Pediatrics and Genetics Department, Faculty of Medicine, Ain Shams University, Cairo, Egypt \\ ${ }^{\mathrm{b}}$ Medical Genetics Center, Faculty of Medicine, Ain Shams University, Cairo, Egypt \\ Tel.: +202 5311741; Fax: +202 2585577; E-mail: nasgenet@hotmail.com
}

\begin{abstract}
Autosomal recessive congenital ichthyosis (ARCI) is a rare heterogeneous keratinization disorder of the skin. It is clinically divided into 2 subtypes, lamellar ichthyosis (LI) and congenital ichthyosiformis erythroderma (CIE). We investigated forty-three ARCI Egyptian individuals in 16 severe LI, and 10 CIE families. We identified 5 alleles in two Egyptian families as having intron-5/exon-6 splice acceptor mutation recognized by the $M s p I$ restriction endonuclease. This promoted to a frequency of $9.6 \%$ for this mutation ( 5 splice-mutation alleles/52 alleles tested). We extended our previous dataset to update the detection of R142H mutation in 4 CIE Egyptian families and one LI phenotype (frequency of $28.8 \%$; 15/52), whereas we still had no $\mathrm{R} 141 \mathrm{H}$ among our Egyptian population. There was no correlation between phenotype and genotype in our study. Surprisingly, the mutant alleles detected in intron-5 acceptor splice-site were associated with the other extreme of CIE phenotypes rather than the severe LI form. We clearly demonstrated that the ARCI Egyptian families in Upper Egypt was ethnically pure and had a tendency not to be a hybrid with other populations in Lower Egypt, Delta zone and Cairo city.
\end{abstract}

\section{Introduction}

Lamellar ichthyosis (LI) is clinically and genetically heterogeneous hereditary keratinization disorder of the skin, which causes abnormalities of the stratum corneum, the upper most layer of the epidermis. In most cases, LI is inherited autosomal recessively. A rare form, however, of autosomal dominantly inherited LI has been described as well [8]. The estimated incidence of autosomal recessive congenital ichthyosis (ARCI) is 1:150,000-300,000 livebirths [26].

Depending on the finding of erythema, two major types of recessive LI were clinically discriminated lamellar ichthyosis (MIM \#242300) and nonbullous congenital ichthyosiform erythroderma [(NCIE) MIM \#242100] [19,24]. The erythematous forms are characterized by prominent erythroderma and fine white, superficial, semiadherent scales. A ninety percent presents at-birth as collodion babies. Patients suffer from palmoplantar keratoderma, often with painful fissures, digital contractures, and loss of pulp volume. In half of the cases, a nail dystrophy including ridging, subugeal hyperkeratosis, or hypoplasia has been described. Ectropion, eclabion (turning outward of the eye lids and lip, respectively), scalp involvement, and loss of eye brows and lashes seem to be more frequent in NCIE than in lamellar ichthyosis [9].

In contrast, for a non-erythematous form presenting at-birth with a collodion-like membrane encasing the neonate, the skin later develops large, brown, platelike scales covering the entire body. Patients may have palmar and plantar hyperkeratosis and significant tautness of the facial skin, which may be associated with ectropion and eclabion. If left untreated, severe ectropion can lead to blindness. Many affected persons exhibit scarring alopecia and secondary hypohidrosis [24]. Two loci for LI had been mapped: LI1, which is caused by mutations in the TGMI gene on 14q11 [18] and LI2, which maps to 2q33-q35 [15]. Fischer et al. [12] identified 2 additional loci for autosomal recessive ichthyosis. One of these was LI3 mapping to chromosome 19 and the other was an erythrodermic form mapping to $3 \mathrm{p} 21$. He reported that linkage to 1 of the 4 loci could be demonstrated in more than half of 51 consanguineous families, most of them from the Mediterranean basin [12]. All 4 loci could be excluded in the others, implying further genetic heterogeneity. 
NCIE can be caused by mutation in the TGM1 [5], arachidonate 12-lipoxygenase, $\mathrm{R}$ type; (ALOX12B) and the arachidonate lipoxygenase 3 (ALOXE3) [25] Jobard et al. [7] identified mutations in lipoxygenase-3 (ALOXE3) and 12R-lipoxygenase (ALOX12B) genes in NCIE linked to chromosome 17. A rare form of NCIE, Chanarin-Dorfman syndrome caused by mutation in the comparative gene identification 58 (CGI58) gene was identified the CGI58 gene in the critical region for triglyceride storage disease with impaired longchain fatty acid oxidation on chromosome 3p21 [3].

A stable cell envelope formed of several components that are covalently bound to each other characterizes the horny cells of the stratum corneum. The components include a number of proteins, such as volucrin, loricrin, and the small proline-rich protein along with lipids on the outer surface of the cell envelope. Transglutaminases are calcium-dependent thiol enzymes that catalyze covalent cross-linking of proteins, thus enhancing the stability of biological structures. These enzymes are present in various tissues and body fluids, such as coagulation factor XII (FXIII) in the blood stream, tissue transglutaminase in red blood cells, liver cells and chondrocytes and keratinocyte and epidermal transglutaminases in the skin [4]. Keratinocyte transglutaminase (TGK) is encoded by the transglutaminase 1 gene (TGM1) on chromosome 14q11 [10]. Moreover, epidermal transglutaminase, which is encoded by the transglutaminase 3 gene (TGM3), is present in suprabasal keratinocytes. TGM3 has been localized to chromosome 20q11-q12 [22,27]. TGM1 catalyzes the formation of covalent $\dot{\varepsilon}$-( $\gamma$-glutamyl)lysine crosslinks between the precursor proteins of the cornified cell envelope (CE). The CE is a 15-20 nm-thick, highly insoluble structure that is formed, during the late phases of epidermal differentiation, on the inner side of the plasma membrane. Several proteins, such as involucrin, loricrin, and the small proline-rich proteins, have been implicated as precursor proteins to the CE. Simultaneously with cross-linking of these precursor proteins, $\Omega$-hydroxyacylsphingosine lipids covalently bounded to the outer surface of the protein $\mathrm{CE}$ and the plasma membrane are replaced by the CE [5]. In patients with autosomal recessive LI, a lack of TGK expression has been shown [1], and linkage of autosomal recessive LI to TGMI has been described [18]. Subsequently, mutations have been identified in the TGM1 in patients with LI [14]. Normal transglutaminase activity and a normal TGMI gene sequence are found in some patients with lamellar ichthyosis, indicating genetic heterogeneity, which was previously suggested on the basis of the ultrastructural analysis of skin biopsies [23]. The splice site mutation is the common TGM1 mutation in congenital recessive ichthyosis patients in the Norwegian population [21].

Our collaborative joint with dermatologists and molecular geneticists of the NIH skin staff since 1992 promoted fruitful results to map the disease locus for the severe autosomal recessive LI to chromosome 14q11 [17] and showed complete linkage of LI disease with TGM1 [18] Those studies had identified no mutations due to $\mathrm{R} 141 \mathrm{H}$ in exon 3, whilst they had been identified the R142H-LI mutation in Egyptian population [17].

\section{Subjects and methods}

\subsection{Selection and categorization of patients}

Thirty patients and thirteen unaffected family members from twenty-six families were studied. The diagnosis of autosomal recessive congenital ichthyosis, on the clinical basis, was made at Medical Genetics Center, Ain Shams University Cairo Egypt following a medical and dermatological history. The 26 families were categorized as sixteen LI and ten CIE type. They were fifteen males and fifteen females. Their onset ages ranged from one day to six years. The 26 ARCI Egyptian families were geographically mapped along with the governorates of Egypt according to the parents' birth origins.

\subsection{Isolation of DNA}

Genomic DNA was extracted from peripheral venous blood-EDTA using QIAamp DNA Mini kit (Qiagen) according to the blood and body fluid spin protocol. In some cases, DNA was prepared in situ by gentle scraping the buccal mucosa for $30 \mathrm{~s}$ using a cytobrush [2]. The cells obtained were treated directly with diluted $\mathrm{NaOH}$ solution, heated, and neutralized with Tris- $\mathrm{Cl}$, pH 8.0 [17].

\subsection{PCR amplification of genomic DNA}

To investigate mutations in exon 3 of TGMI gene, we amplified this exon using oligonucleotide primer pairs designed by Russell et al. [17] Both genomic DNA (200 ng) prepared from the whole blood or from buccal mucosa $(5 \mu \mathrm{l})$, primers (100 $\mathrm{nM}$ each), were premixed with $200 \mu \mathrm{M}$ dGTP, dATP, dCTP, dTTP in $10 \mathrm{mM}$ Tris- 
$\mathrm{HCl}, 50 \mathrm{mM} \mathrm{KCl}, 1.5 \mathrm{mM} \mathrm{MgCl}_{2}$ in a total volume reaction of $30 \mu \mathrm{l}$. The Red $\operatorname{Taq}^{\circledR}$ enzyme $1.5 \mathrm{U}$ was added to the reaction mixture and denatured at $94^{\circ}$ for $2 \mathrm{~min}$, then they are amplified at $94^{\circ}$ for $60 \mathrm{~s}, 60^{\circ}$ for $30 \mathrm{~s}$, and $72^{\circ}$ for $90 \mathrm{~s}$, and an extension for $10 \mathrm{~min}$ after 35 cycles. Amplification products from each primary PCR (295-bp) was diluted 1:500, and $5 \mu$ l was re-amplified using the same primers and conditions in a 100- $\mu$ l-reaction mixture. The secondary PCR amplicons were separated on 2\% agarose gel (Promega) and purified, if necessary, with the Wizard PCR Prep kit (Promega).

\subsection{Restriction enzyme analysis}

The PCR amplicon was subjected to cutting with restriction enzymes ApaLI and AciI. If R $141 \mathrm{H}$ mutation is present, the 295-bp product will be cleaved into 142 and 153 fragments, otherwise no cleavage will be the case. Using 10 units AciI endonuclease, the 295-bp product would be digested into four fragments 107 , 100,53 and 35 on a $2 \%$ MetaPhor (BMA) gel. The mutation removes two adjacent $A c i$ I sites so that digests of affected individuals reveal the presence of a 160bp bands and loss of the 107-bp and 53-bp fragments. Heterozygotes have both the 160-bp and 107-bp bands.

\subsection{Intron 5 splice acceptor mutation analysis}

To assess the presence of the intron 5 splice acceptor site mutation in TGM1, genomic DNA (200 ng) prepared from the whole blood or from buccal mucosa $(5 \mu \mathrm{l})$ was amplified with Red Taq enzyme (Sigma) using the oligonucleotide pair TGM1mutF and TGM1mutR [28]. PCR was performed for 35 cycles of $94^{\circ}$ for $15 \mathrm{~s}, 60^{\circ}$ for $30 \mathrm{~s}$, and $72^{\circ}$ for $45 \mathrm{~s}$ with extension at $72^{\circ} \mathrm{C}$ (PCRexpress, Hybaid). The products were analyzed on $2 \%$ agarose gel, and DNA fragments were cut out and purified, if necessary. The TGMI intron 5 acceptor splice site mutation was confirmed in affected individuals and carriers by MspI digestion [20]. The mutation created an additional MspI restriction site, so that cleavage of the 467-bp PCR fragment generated from genomic DNA resulted in two specific fragments of 298-bp and 169-bp. The digested PCR products were electrophoresed on $2 \%$ MetaPhor agarose.

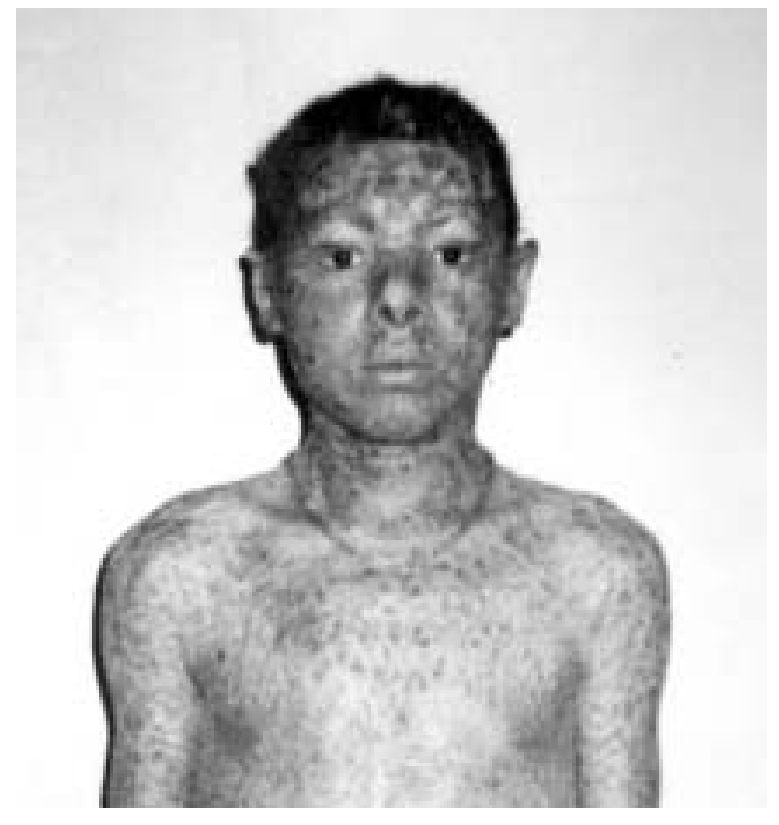

Fig. 1. Photograph shows a 15-year-old CIE male Egyptian patient.

\section{Results}

\subsection{Phenotypic expression}

The twenty-six families with ARCI were investigated clinically and molecularly. The clinical picture of the patients analyzed was highly variable. Seven of them were born as collodion babies, three showed joint contractures and the last showed alopecia. Fourteen patients suffered from erythema accompanied in the more severely affected cases by ectropion, whereas sixteen patients from different families were presented with the non-erythrodermic form of LI. The type of scaling was highly variable, ranging from fine whitish scales to dark brownish scales. All but two showed positive consanguinity ( 3 were 3 rd degree relatives and 21 were 2 nd degree relatives) and fifteen showed positive family history. The clinical features of the affected ARCI were represented in Table 1.

\subsection{Mutational analysis}

\subsubsection{R142H mutation in TGM1 gene}

We detected a homozygous R142H-mutation in exon 3 detected by AciI recognition site in the LI-proband (I-59) of 2.5-year-old. The patient was the 1st offspring of consanguineous parents with 2 similarly affected females and one neonatal-death male with the same condition. The presenting symptoms started since birth 
Table 1

Clinical phenotypes of 6 affected families with intron 5 splice site acceptor and R142H mutations in TGM1

\begin{tabular}{|c|c|c|c|c|c|c|c|c|c|}
\hline \multirow[t]{2}{*}{ Case } & \multirow[t]{2}{*}{ Sex } & \multirow[t]{2}{*}{$\operatorname{Age}^{\mathrm{a}}$} & \multirow{2}{*}{$\begin{array}{c}\text { Skin at } \\
\text { birth }\end{array}$} & \multirow[t]{2}{*}{ Scales } & \multirow[t]{2}{*}{ Phenotypes } & \multicolumn{3}{|c|}{ Severity of $T G M 1$ disease } & \multirow{2}{*}{$\begin{array}{l}\text { Treatment } \\
\text { history }\end{array}$} \\
\hline & & & & & & Ectropion & Palmo-planter HK & Alopecia & \\
\hline I-59 & Male & $2.5 y$ & $?$ & + & LI & - & + & - & VA, U \\
\hline III-46 & Male & $2 y$ & Collodion & + & CIE & + & + & - & SPB, VA, U, AHA, PG \\
\hline VI-16 & Female & $12 y$ & Collodion & + & CIE & - & + & + & VA, U, AHA \\
\hline VI-17 & Female & $30 \mathrm{y}$ & - & - & CIE & - & + & - & $\mathrm{U}, \mathrm{AHA}$ \\
\hline VI-26 & Female & $20 y$ & $?$ & + & $\mathrm{CIE}+\mathrm{XP}^{\mathrm{b}}$ & - & + & - & VA, PG \\
\hline VI-64 & Female & $1 \mathrm{y}$ & - & + & CIE & - & - & - & $\mathrm{U}, \mathrm{PG}, \mathrm{LA}$ \\
\hline VII-20 & Male & $1 d$ & - & + & CIE & + & + & - & VA, PG, LA \\
\hline IX-28 & Male & $1.5 \mathrm{y}$ & Collodion & + & CIE & - & + & - & AHA, PG, U \\
\hline$X-40$ & Female & $3.5 y$ & - & + & CIE & - & - & - & AHA \\
\hline
\end{tabular}

a Age at time of diagnosis.

b Xeroderma pigmentosum associated with convulsions.

$\mathrm{VA}=$ vitamin $\mathrm{A}, \mathrm{U}=$ urea, $\mathrm{AHA}=$ alpha-hydroxy acids, $\mathrm{PG}=$ polyethylene glycol, $\mathrm{SPB}=$ sodium phenobarbitone, $\mathrm{LA}=$ lactic acid.

with generalized erythroderma followed by scaling of skin, dark scales affecting the entire body with exaggeration over flexural and pressure areas with itching associated with flexion deformity of the fingers and deviation of hands. The erythroderma was attenuated on treatment with oral vitamin A and topical urea. The unaffected father (I-69) revealed a heterozygous R142H mutation.

A 2-year-proband classical CIE type (III-46) revealed a homozygous $\mathrm{R} 142 \mathrm{H}$ mutation recognized with AciI enzyme. He had had multiple skin ulcerations together with scales distributed allover the body, ectropion and eclapion including scalp scaring (Fig. 1) with a collodion baby on birth. Treatment with oral vitamin A, topical use of urea, alpha- and poly-hydroxy acids, showed an excellent response on following up during one year. His mother (III-70) revealed a heterozygous mutation towards the same R142H mutation.

A 12-year-old female CIE patient (VI-16) showed homozygosity towards the R142H mutation. She was presented with dry rough scaly skin covering the whole body with dark areas over the elbows and knees, starting the case since birth. Her affected mother (VI-17) showed a heterozygous R142H mutation manifesting mild scaling localized to the legs and arms and roughness of skin of palms and soles. They were treated with oral vitamin $\mathrm{A}$, and topical hydroxy acids and urea showing a good response. A female patient of 20 years (VI-26) was birthed with a collodion membrane that shed off after one week leaving erythrodermatous surface followed by scales covering all over the body, more severely on the pressure areas (elbows \& knees). In winter, the condition worsens where the scales are moderate in size, adherent and soft. The symptoms had followed with attacks of tonic-clonic convulsions and psychomotor epilepsy associated with xeroderma pigmentosum showing multiple brownish macules over the upper part of the neck, trunk and hands. This case was fairly attenuated with oral vitamin A. It was of interesting to note that the splice site mutation abnormally existed in family VI besides R142H mutation common in this family (Fig. 2).

Family (VII) showed an inclusion of homozygous R142H-mutation CIE patient (VII-20) with one-dayage having a dry rough scaly skin all over the body with erythema and scaring with deformity of hands and feet, scaring the scalp, palms and soles. Also, he had not a developed ear, depressed nasal bridge and a severe ectropion. Treatment included oral vitamin A and topical keratolytics. The heterozygous mother (VII-21) was followed up in our dermatological clinic for genetic counseling for a neonatal-death female with a similar case (not examined).

A CIE-family showed a proband (IX-28) of 1.5-yearold that is the first sibling of two consanguineous parents. At birth, he was covered with a collodion membrane that shed off leaving scales all over the body with generalized erythroderma. The scales were small, dark and adherent. The patient was treated with topical glycolic acid, lactic acid and urea. The unaffected mother (IX-29) has a heterozygous R142H mutation.

\subsubsection{Intron 5 splice acceptor site mutation}

Two individuals with autosomal congenital recessive ichthyosis (ARCI) and a mutation in the intron 5/exon 6 canonical splice site in TGM1 were identified in two families.

Family VI was intensively investigated where it included 5 phenotypically CIE patients and their mild affected mother (VI-17) living in the far south of Upper Egypt. We detected here only one homozygous sibling (VI-64) as having intron 5 splice acceptor mutation. She is a one-year-old female CIE patient being the 4 th offspring of proband sibship of consanguineous 


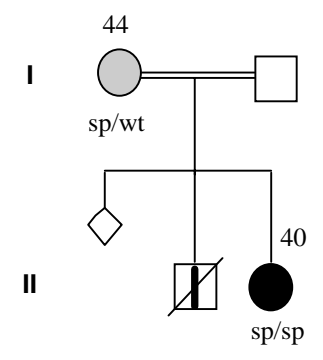

Family $\mathbf{X}$

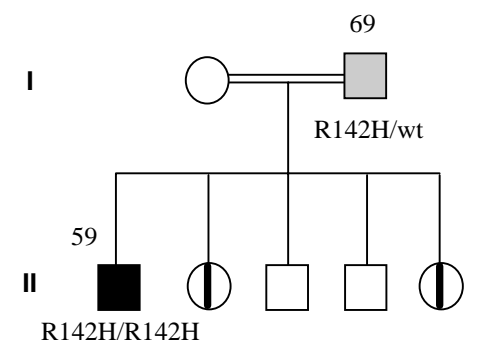

Family I
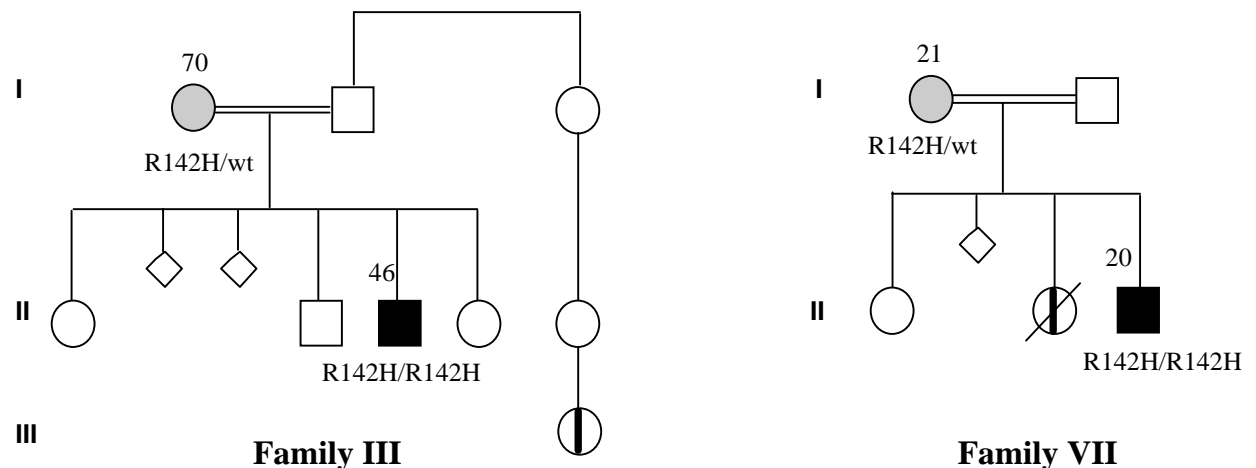

Family VII

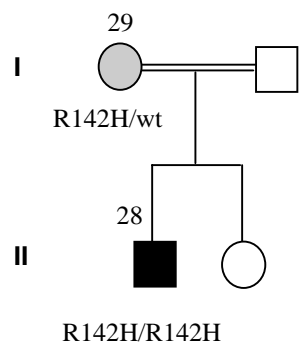

Family IX
I

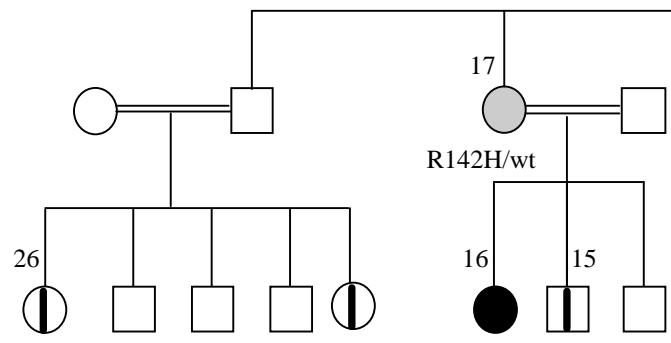

$\mathrm{R} 142 \mathrm{H} / \mathrm{R} 142 \mathrm{H}$

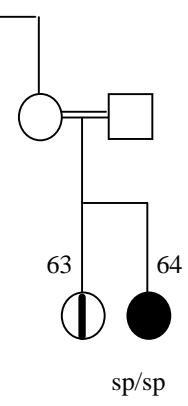

Family VI

Fig. 2. Pedigrees of 6 families with both R142H and 5 intron/exon 6 acceptor site mutations.

parents. She was presented with generalized small fine white scales allover the body. The condition was started at a 3-day-age by roughness and dry scaly skin over the wrist joint then became generalized. The condition was associated with tonic-clonic convulsions started at the age of $10 \mathrm{~m}$. The proband was fairly improved with a phenobarbitone salt as an anticonvulsant, and topical urea. Another 3.5-year-old CIE female (X-40) showed the same splice-site mutation in intron 5/exon 6 manifesting a homozygous mutation. Her condition started to be noticed at birth by dry rough scaly skin all over the body associated with itching and erythrema. Her mother (X-44) showed a heterozygous allele manifestation.

\section{Discussion}

\subsection{Geographical analysis}

The ARCI twenty-six patient families (43 individuals) were selected from the genodermatosis database 
records in ASMGC. Those families were categorized as having severe LI and CIE the other extreme of the disease. The demographic distribution within the regional map of Egypt revealed that the frequency of the ARCI families in Upper Egypt was lower than in Nile Delta zone, Cairo, and Lower Egypt. This might be due to the tendency of Upper Egyptians to be isolated from other governorates of Egypt due to restricted habits and social rules. This was clearly confirmed by the existence of only one CIE family (VI) living in the far south to Aswan (Fig. 2). Unfortunately, there are no TGM1 mutational studies in the Arabs' area, except those in Northern Africa due to TGM2 gene on chromosome $2 q 34,(15,16)$ though there is a strong observation for an inclusion of ARCI in the Gulf area.

\subsection{Mutational analysis}

We screened both LI and CIE individuals for the intron 5 splice acceptor mutation previously described by Huber et al. [20] Surprisingly, we have investigated and identified three-CIE-patient-Egyptian individuals having splice acceptor mutation in the TGM1 due to a change of $A$ to $G$ at position 56 in genomic DNA. Therefore, this indicated that that mutation has not been limited to the Norwegian and German populations [28]. Of 26 families from whom DNA were available, we identified 2 families who carried the intron $5 \mathrm{G}>A$ acceptor-site mutation revealing 2 homozygous and 1 heterozygous alleles. This gives a frequency of $9.6 \%$ for the splice mutation allele in our data $(5$ splicemutation alleles/52 alleles tested). This is a clinically high heterogeneous group of families and no conclusions about the frequency of this mutation in ARCI can be derived directly from this dataset.

After identifying the splice-site mutation in Egyptian ARCI patient' families, we moreover investigated $\mathrm{R} 141 \mathrm{H}$ and $\mathrm{R} 142 \mathrm{H}$ in exon 3 of the TGM1. Extra genomic DNA screening for $\mathrm{R} 141 \mathrm{H}$ of the TGM1 revealed the absence of this mutation in Egyptian population which confirmed the previous pilot study [17]. An extension to the previous results discussed by the ASMGC-NIH joint staffs was carried out using the newly banked genomic DNA samples. We identified 5 homozygous probands carrying the $\mathrm{R} 142 \mathrm{H}$ mutation and 5 heterozygous carriers with a frequency of $28.8 \%$ (15 mutant $\mathrm{R} 142 \mathrm{H}$ alleles/52 alleles tested). The mutation in each of the five families segregated with the disease. In those families $\mathrm{G}$ to $\mathrm{A}$ transitions in CGC codons in exon 3 results in single amino acid substitutions either R141H or R142H. Again, deamination of 5-methylcytosine associated with methylation of $\mathrm{CpG}$ dinucleotides has been suggested to interpret the high frequency of $C>T$ or $G>A$ transitions causing the genetic disease [11].

\subsection{Genotype/phenotype correlation}

Autosomal recessive LI is characterized by remarkable clinical heterogeneity. An erythematous and a nonerythematous type of LI were clinically distinguished [19,24] Moreover, patients might exhibit different clinical patterns and colors of the scales, they might or might not have an inclusion of palmoplantar hyperkeratosis, and not all of them were born as collodion babies. The whole spectrum of LI variants, however, was also seen in TGM1 LI patients (Table 1) in family IV (Fig. 2). Seeking a genotype/phenotype correlation for specific mutations in TGM1 gene, we were able to compare two patients who carry the same TGM1 genotype. Both III-46 and X-40 were homozygous for the splice 5 intron acceptor site mutation, but they differed in their clinical picture despite having erythrematous skin scales as illustrated in Table 1. Hence, there were no conclusive criteria for the clinical differentiation of the two extremes of LI and CIE phenotypes. The phenotype/genotype correlation and heterogeneity of the ARCI may be identified and interpreted by extending studies to other loci linked to the disease.

\subsection{ARCI treatment}

In this study, we obtained detailed clinical information about each of the patients, including topical treatment and oral medication history particularly the oral vitamin A, topical alpha- and poly-hydroxy acids and ureas. We have observed for the initiation of the effective therapy, 50 to $100 \mathrm{mg}$ vitamin A have to be administered orally which is the upper limit of toxic effects. The oral dose may be optimally reduced to $20 \mathrm{mg}$ twice daily and after 4 weeks to about $10 \mathrm{mg}$ twice daily. Stopping the treatment and reappearance of ichthyotic lesions, oral vitamin $\mathrm{A}$ at a lower dose 10 to 20 is well tolerated by most patients with satisfactory results. It was shown that urea strongly increased water-binding capacity of the scales several days after the last treatment and the transepidermal water loss was reduced [13]. It is noteworthy that the high concentration of urea in a basic cream represents highly potent agent than other keratolytics for treating ichthyosis vulgaris-like phenotypes. Moreover, alpha- and polyhydroxy acids restore toward normal the hyperkera- 
totic skin of the ichthyoses. The sequence of the histologic and clinical changes in lamellar ichthyosis suggests that the effect of those hydroxy compounds on the skin are mediated by means of their influence at the level of underlying epidermis in so far as after several days of topical treatment a normal skin surface abruptly appears clinically, consequent to sheet-like desquamation of the entire thickened stratum corneum without dissolution [6].

\section{Acknowledgments}

We thank Drs. S. Bale, J. DiGiovanna, and J. Compton, the skin staff of National Institutes of Health (NIH) through their collaboration since 1992 till 2001 via USgrant \#E-05-N and \#BIO-002-025. We wish to thank the families for their willing to participate in our research study.

\section{References}

[1] A.P. Lavrijsen and T. Maruyama, Absent transglutaminase TGK expression in two of three patients with lamellar ichthyosis, Arch Dermatol 131 (1995), 363-364.

[2] B. Richards, J. Skoletsky, A.P. Shuber, R. Balfour, R.C. Stern, H.L. Dorkin, R.B. Parad et al., Multiplex PCR amplification from the CFTR gene using DNA prepared from buccal brushes/sawbs, Hum Mol Genet 2 (1993), 159-163.

[3] C. Lefevre, F. Jobard, F. Caux, B. Bouadjar, A. Karaduman, R. Heilig, H. Lakhdar, A. Wollenberg, J.L. Verret, J. Weissenbach, M. Ozguc, M. Lathrop, J.F. Prud'homme and J. Fischer, Mutations in CGI-58, the gene encoding a new protein of the estrase/lipase/ thioestrase subfamily, in Chanarin-Dorfman syndrome, Am J Hum Genet 69(5) (2001), 1002-1012.

[4] D. Aeschlimann and M. Paulsson, Transglutaminases: protein cross-linking enzymes in tissues and body fluids, Thromb Haemost 71(4) (1994), 402-415.

[5] E. Laiho, J. Ignatius, Hmikkola, V.C. Yee, D.C. Teller, K.-M. Niemi, U.S. Kere, J. Kere and A. Palotie, Transglutaminase 1 mutations in autosomal recessive congenital ichthyosis: private and recurrent mutations in an isolated population, $A m \mathrm{~J}$ Hum Genet 61 (1997), 529-538.

[6] E.J. Van Scott and R.J. Yu, Control of keratinization with ahydroxy acids and related compounds, I. Topical treatment of ichthyotic disorders, Arch Dermatol 110 (1974), 586.

[7] F. Jobard, C. Lefevre, A. Karaduman, C.B. Bardon, S. Emre, J. Weissenbach, M. Ozguc, M. Lathrop, J.-F. Prud'homme and J. Fischer, Lipoxygenase-3 (ALOXE3) and 12(R)-lipoxygenase (ALOX12B) are mutated in non-bullous congenital ichthyosiform erythroderma (NCIE) linked to chromosome 17p13.1, Hum Mol Genet 11 (2002), 107-113.

[8] H. Traupe, G. Kolde and R. Happle, Autosomal dominant lamellar ichthyosis: in a new skin disorder, Clin Genet $\mathbf{2 6}$ (1984), 457-461.

[9] H. Traupe, The ichthyosis: a guide to clinical diagnosis, genetic counseling, and therapy, Springer, Berlin, 1989.
[10] I.-G. Kim, O.W. McBride, M. Wang, S.-Y. Kim, W.W. Idler and P.M. Steinert, Structure and organization of the human transglutaminase 1 gene, J Biol Chem 267 (1992), 7710-7717.

[11] J. Cheng et al., The genetic basis of epidermolytic hyperkeratosis: a disorder of differentiation-specific epidermal keratin genes, Cell 70 (1992), 811-819.

[12] J. Fischer, A. Faure, B. Bouadjar, C.B. Bardon, A. Karaduman, I. Thomas, S. Emre, S. Cure, M. Ozguc, J. Weissenbach and J.F. Prud'homme, Two new loci for autosomal recessive ichthyosis on chromosomes 3 p21 and 19p12-q12 and evidence for further genetic heterogeneity, Am J Hum Genet 66 (2000), 904-913.

[13] K. Grice, H. Sattar and H. Baker, Urea and retinoic acid in ichthyosis and their effect on transepidermal water loss and water holding capacity of stratum, Acta Dermat (Stockholm) 53 (1973), 114.

[14] L. Parmentier, C.B. Bardon, S. Nguyen, J.F. Prud'homme, L. Dubertret and J. Weissenbach, Autosomal recessive lamellar ichthyosis: identification of a new mutation in transglutaminase 1 and evidence for genetic heterogeneity, Hum Genet 4 (1995), 1391-1395.

[15] L. Parmentier, C. Clepet, O.B. Stambouli, H. Lakhdar, C.B. Bardon, S. Marchand, L. Dubertret, E. Wunderle, F. Pulcini, C. Fizames and J. Weissenbach, Lamellar ichthyosis: Further narrowing, physical and expression mapping of the chromosome 2 candidate locus, Eur J Hum Genet 7 (1999), 77-87.

[16] L. Parmentier, H. Lakhdar, C.B. bardon, S. Marchand, L. Dubertret and J. Weissenbach, Mapping of a second locus for lamellar ichthyosis to chromosome 2q33-35, Hum Mol Genet 5 (1996), 555-559.

[17] L.J. Russell, J.J. DiGiovanna, G.R. Rogers, P.M. Steinert, N. Hashem, J.G. Compton and S.J. Bale, Mutations in the gene for transglutaminase 1 in autosomal recessive lamellar ichthyosis, Nat Genet 9 (1995), 279-283.

[18] L.J. Russell, J.J. DiGiovanna, N. Hashem, J.G. Compton and S.J. Bale, Linkage of autosomal recessive lamellar ichthyosis to chromosome 14q, Am J Hum Genet 55 (1994), 1146-1152.

[19] M. Hazell and R. Marks, Clinical, histologic and cell kinetic discriminants between lamellar ichthyosis an nonbullous congenital ichthyosiform erythroderma, Arch Dermatol 121 (1985), 489-493.

[20] M. Huber, I. Rettler, K. Bernasconi, E. Frenk, S.P. Lavrijsen, M. Ponec, A. Bon et al., Mutations of keratinocyte transglutaminase in lamellar ichthyosis, Science 267 (1995), 525-528.

[21] M. Pigg, T.G. Dahl Jr., D. Cox, I. Hausser, I.A. Lamprecht and N. Dahl, Strong founder effect for a transglutaminase 1 gene mutation in lamellar ichthyosis and congenital ichthyosiform erythroderma from Norway, Eur J Hum Genet 6 (1998), 589596.

[22] M. Wang, I.G. Kim, P.M. Steinert and O.W. McBride, Assignment of the human transglutaminase 2 (TGM2) and transglutaminase 3 (TGM3) genes to chromosome 20q11.2, Genomics 23 (1994), 721-722.

[23] M.-L. Arnold, I.A. Lamprecht, B.M. Rothfuss and W. Hartschuh, Ichthyosis congenita type III: Clinical and ultrastructural characteristics and distinction within the heterogeneous ichthyosis congenita group, Arch Derm Res 280 (1988), 268-278.

[24] M.L. Williams and P.M. Elias, Heterogeneity in autosomal recessive ichthyosis: clinical and biochemical differentiation of lamellar ichthyosis and nonbullous congenital ichthyosiform erythroderma, Arch Derm 121 (1985), 477-488.

[25] P. Krieg, F. Marks and G. Furstenberger, A gene cluster encoding human epidermis-type lipoxygenases at chromosome 
17p13.1: cloning, physical mapping and expression, $G e$ nomics 73(3) (2001), 323-330.

[26] S.J. Bale and S.Z. Doyle, The genetics of ichthyosis: a primer for epidemiologist, J Invest Dermatol 102 (1994), 49-50.

[27] V. Gentile, P.J. Davies and A. Baldini, The human tissue transglutaminase gene maps on chromosome $20 q 12$ by in situ flu- orescence hybridization, Genomics 20 (1994), 295-297.

[28] Y.O. Shevchenko, J.G. Compton, J.R. Toro, J.J. DiGiovanna and S.J. Bale, Splice-site mutation in TGM1 in congenital recessive ichthyosis in American families: molecular, genetic, genealogic and clinical studies, Hum Genet 106 (2000), 492493. 


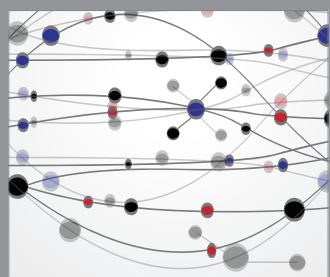

The Scientific World Journal
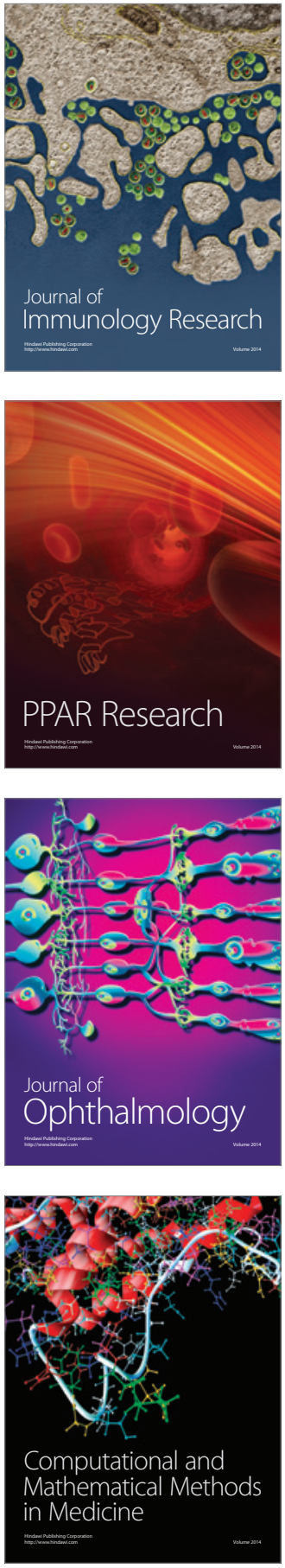

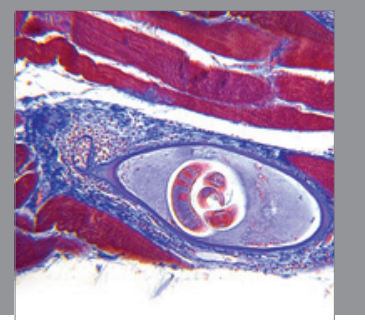

Gastroenterology

Research and Practice
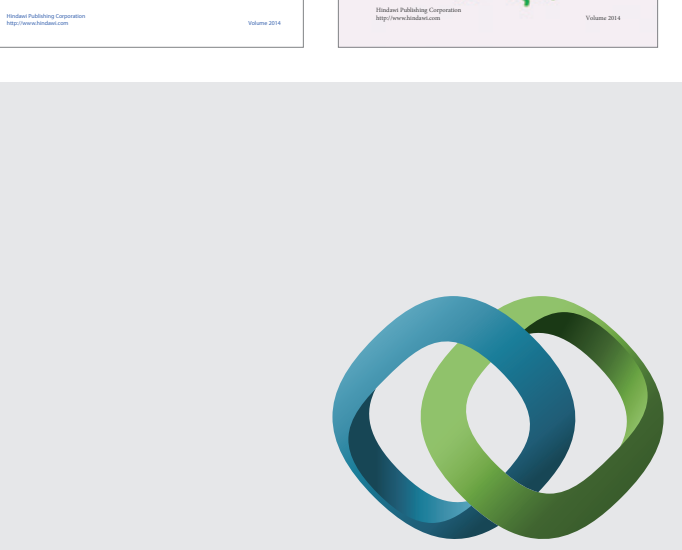

\section{Hindawi}

Submit your manuscripts at

http://www.hindawi.com
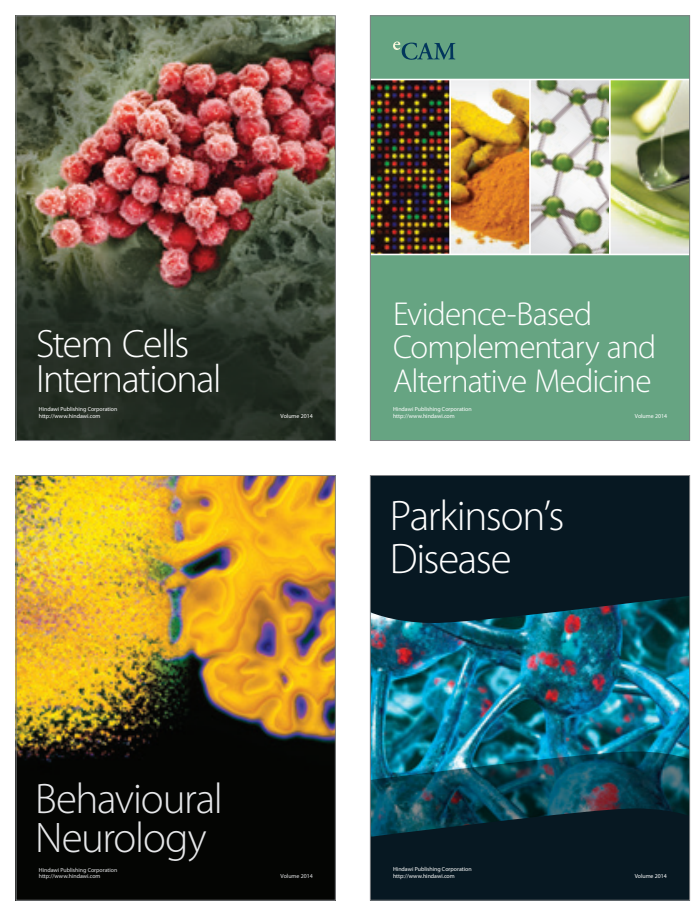

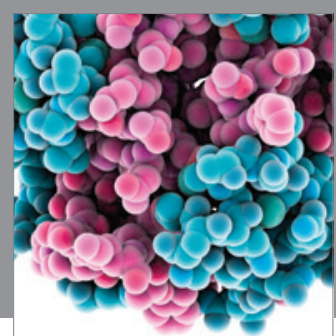

Journal of
Diabetes Research

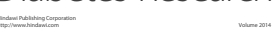

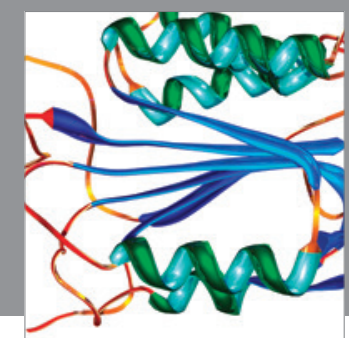

Disease Markers
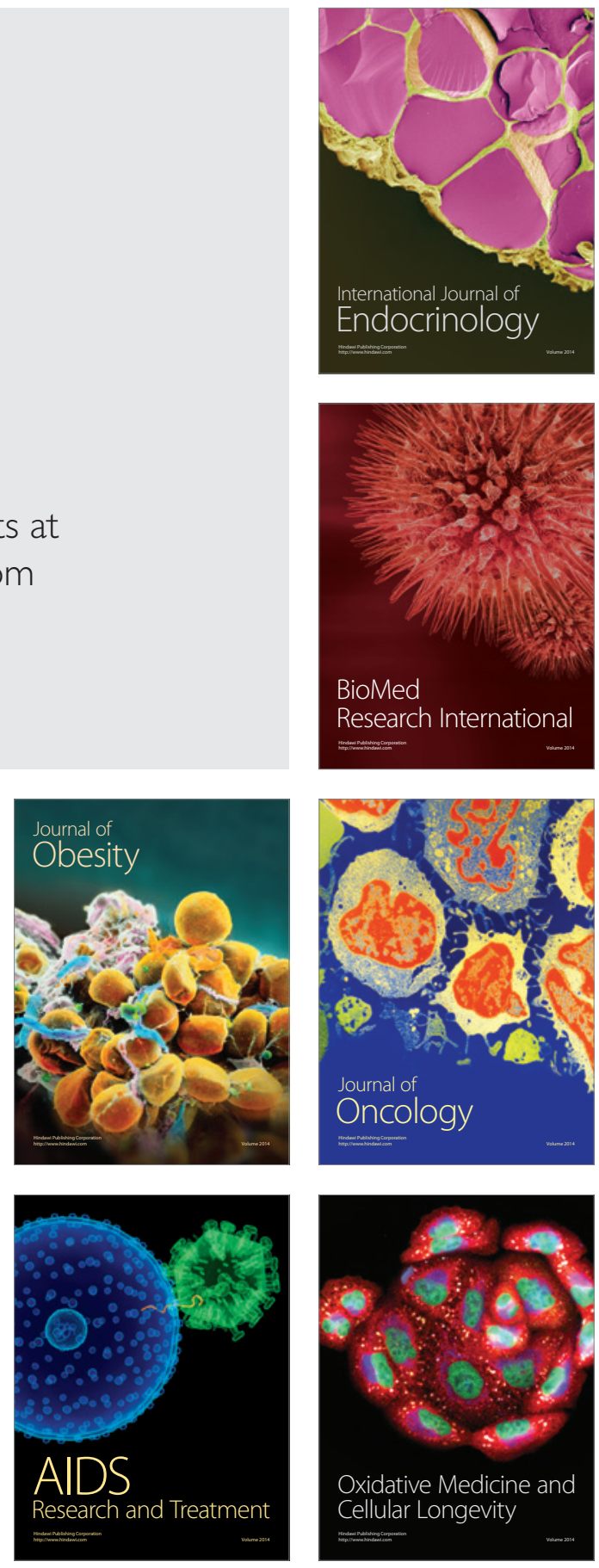